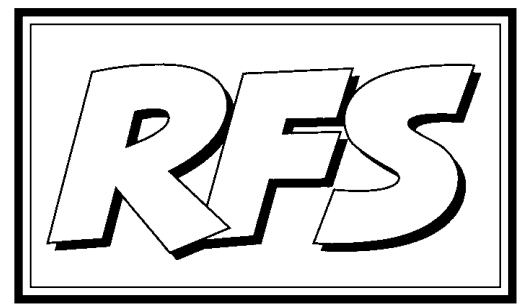

Revista de Fomento Social, 53 (1998), 313-343

\title{
La política económica del gobierno popular: España, ¿va bien?
}

Consejo de Redacción

«En consecuencia, siempre que cierto número de hombres se une en una sociedad renunciando cada uno de ellos al poder de ejecutar la ley natural, cediéndolo a la comunidad, entonces y sólo entonces se constituye una sociedad política o social».

Al leer el título del editorial, alguno de nuestros lectores podría pensar que es demasiado pronto para hacer un balance del gobierno del PP. La Revista de Fomento Social publicó en sus números 189 y 190 del año 1993 sendos comentarios editoriales haciendo balance de la acción política del gobierno

(1) JoHN LocKe [1690] (1983) Ensayo sobre el gobierno civil. Ed. Orbis, p. 69. 
socialista, tanto en sus aspectos económicos como en los políticos propiamente dichos. Titulamos entonces aquellos editoriales «La década de gobierno socialista: un balance político y un balance económico», respectivamente. Creemos, sin embargo, que no hay que esperar 10 años (i) para hacer una evaluación, todo lo provisional que se quiera, sobre la acción de gobierno del Partido Popular. Desde aquel 3 de marzo de 1996, en que el partido de Aznar ganó las elecciones, ha transcurrido un tiempo suficiente; ya bien entrado el tercer año de legislatura, hay elementos para emitir un juicio: han pasado muchas cosas, algunas de importancia. Contraponer dos períodos de tiempo tan desiguales no sería adecuado, si no fuera porque este gobierno, que nació débil e hipotecado por los pactos «contra naturam» con los nacionalismos, se ha consolidado en las encuestas y ha hecho posible un gobierno de la derecha democrática en España, algo impensable hace unos lustros.

\section{Delimitación del tema y de la perspectiva de esta reflexión}

En este artículo editorial vamos a repasar los principales aspectos relacionados con la política económica y social, dejando para un comentario ulterior un análisis de los más convencionalmente políticos; hacemos esa separación por razones prácticas, a sabiendas de que se trata de una distinción un tanto falaz, porque la política económica es, ante todo, política (2). Ese análisis pendiente será seguramente menos positivo que el de los aspectos económicos: en el terreno de la política general los claroscuros son mucho más marcados que en todo lo concerniente a la economía (3).

Advertimos que no pretendemos hacer un estudio exhaustivo de política económica. Su amplitud desbordaría la extensión razonable de un artículo editorial al estilo de nuestra revista, ya de por sí largo. Recogemos aquellos aspectos que nos han parecido más relevantes, a sabiendas de que quedan sin

(2) Es sabido que rara es la acción política que, sin ser propiamente política económica, no tenga efectos económicos. No nos vamos a referir a este concepto tan general.

(3) Se nos ocurre pensar que las personas concretas que ocupan las dos vicepresidencias, económica (Rodrigo RATO) y política (FrANCISCO Álvarez CASCOS), simbolizan también dos modos y estilos de hacer política que-dados los problemas en cuestión-parecen exigir talantes muy diferentes... 
tratar temas de interés; daremos especial relevancia a los elementos de comparación con el gobierno anterior. En todo caso valga esta advertencia como aviso y excusa de que no pretendemos agotar el tema... (4).

¿Desde dónde hacemos esta crítica? Se trata de una cuestión relevante. La polarización política de la sociedad española -probablemente más aguda y estentórea la expresada en los medios de comunicación que la del tejido social propiamente dicho en su conjunto-hace que cualquier reflexión crítica emitida sobre la acción del gobierno sea interpretada inmediatamente en función de claves previas de posicionamiento político partidista. Si queremos hacer un juicio sobre la política económica, seguramente el ámbito más exitoso del actual gobierno, navegamos peligrosamente entre dos escollos; por un lado, hay que sortear a Scilla, que consiste en sumarse al coro de los que cantan al unísono aquello de «España va bien»; pero tampoco queremos encallar contra Caribdis, personificado en la descalificación que sistemáticamente suelen realizar los partidos situados en la oposición (5). Según este último enfoque, se esperaría una descalificación total, dado que se está enjuiciando al «adversario» político, a fin de cuentas aquél que cierra el camino al poder (6).

Porúltimo, no quisiéramos que estas páginas fueran interpretadas como una sobrevaloración del papel de los gobiernos en la política económica como parece derivarse de la obsesiva preeminencia que los medios de comunicación conceden a la información política. En nuestra opinión, la actividad gubernamental debe situarse en un marco más complejo, del que forman parte, no sólo

(4) También nos desborda el análisis de la política de los gobiernos populares autonómicos y municipales. Sin embargo es una tarea demasiado poco abordada, y que debería ser acometida por su gran importancia dada su gran repercusión en la vida diaria y real de los ciudadanos.

(5) Curiosamente, lo critica por supuesto el PSOE, pero también-quizás con una alternativa más coherente-IU, sin que faltan voces liberales que claman ante lo conservador, en el sentido literal del término, de este gobierno...

(6) Tal es, por ejemplo, la sensación que produce el reciente documento del GruPO Parlamentario Socialista.- «Informe ante el inicio del periodo de sesiones» del 15 de septiembre de 1998; a la vez que aporta interesantes elementos de crítica a la acción del gobierno, nada de lo que ha hecho el gobierno popular «se salva de la quema»; todo está mal, sin excepciones. Una descalificación tan universal y sin matices se descalifica a símisma. Esa postura de desautorización total es tanto más sorprendente cuanto-como vamos a ver-en la substancia, los elementos de continuidad y de semejanza entre las políticas económicas de ambos gobiernos son mucho más abundantes y significativos que los de discontinuidad o ruptura. 
la coyuntura internacional, especialmente europea, sino también la acción del conjunto de la sociedad representada por las empresas (grandes y pequeñas), los sindicatos, las asociaciones intermedias, la sociedad civil, los ciudadanos etc. La situación económica es el resultado de la acción agregada de las fuerzas vivas ciudadanas, y no sólo de la actuación del gobierno de turno.

Las reflexiones que siguen no pretenden un tratamiento sistemático y exhaustivo de toda la política económica. Hemos preferido seleccionar con criterios didácticos los que nos parecen los aspectos más significativos de dicha política, admitiendo que en esa selección hay ya una valoración implícita. Son los siguientes:

- Política de convergencia

- Política monetaria y financiera

- Política de empleo y de concertación social

- Política de bienestar

- Política tritbutaria

- Política de privatizaciones

- Algunas políticas «descuidadas»

Para terminar, en las conclusiones intentaremos ofrecer algunas reflexiones valorativas de carácter sintético.

\section{Política de convergencia: salieron las cuentas}

A cuantos hemos seguido desde hace años el proceso de unificación monetaria europea (7), no pueden menos de parecernos casi increíbles las palabras (que se repiten textualmente, como un estribillo, para todos los países «aprobados») del resumen del dictamen de la Comisión sobre el cumplimiento de las condiciones de convergencia para pasar a la tercera fase de la unión monetaria: «Evaluado el cumplimiento de los criterios de convergencia, la Comisión considera que España ha alcanzado un alto grado de convergencia sostenible» (8).

(7) Véase, por ejemplo, nuestro propio artículo editorial del no 205, enero-marzo 1997, titulado: «La Moneda Única: ¿merece la pena? ¿y después qué?», en el que todavía dudábamos de las posibilidades de la economía española de incorporarse al grupo de cabeza de la moneda única europea. Cf. p. 11.

(8) Comisión Europea (1998).-- Informe de convergencia 1998. (Elaborado de conformi- 
La convergencia es uno de los principales logros conseguidos bajo el gobierno del Partido Popular, y constituía sin duda el norte de toda su política económica: ha cumplido plenamente ese objetivo, a saber, que España ingrese desde el primer momento en la Unión Monetaria (UM), junto con otros 10 países. Esto ha implicado la necesidad de cumplir con los criterios de convergencia establecidos en el Tratado de Maastricht, ya muy conocidos.

En realidad, en el momento de su ingreso en la UM (mayo de 1998) España sólo cumplía en estricto rigor cuatro de los cinco criterios exigidos. Su deuda pública, en efecto, ascendía en ese momento al 68\% del PIB. Pero este criterio ha sido interpretado en el marco del Tratado de Maastricht que permite una cierta holgura en relación con el grado de cumplimiento de los criterios de déficit público y, sobre todo, de deuda pública. De no haber sido así, ni Bélgica ni Italia, por ejemplo, hubieran podido entrar, dado el volumen excesivo de su deuda pública. Más aún, en el momento del examen sólo Luxemburgo cumplía estrictamente con los cinco criterios.

Sin duda, este ha sido un gran éxito de la política económica del PP. De cómo se ha logrado hablaremos más adelante. Pero, por otro lado, al margen de la aspiración al ingreso en la UM, la política de convergencia se considera en cualquier caso necesaria y conveniente para satisfacer los intereses generales de la economía española en el entorno competitivo europeo en el que se desenvuelve, especialmente desde la puesta en marcha del Mercado Único. ¿Quién puede negar que -pese a que no han faltado ciertos «maquillajes» en las cuentas públicas (como, por cierto en otros países de la UE) para poder pasar decorosamente el examen de convergencia de primeros de mayo-es meritorio rebajar el déficit público del 4,5\% del PIB en 1996 al 2,9\% a finales de 1997, y la deuda pública del 74,6\% del PIB en 1996 al 68\% a finales de 1997? (9).

Por otra parte el descenso de la inflación medida por el IPC del 3,4\% en 1996 al 2,2\% a finales de 1997 ha sido también muy positivo -por varias razones-

dad con el apartado 1 del artículo 109 J del Tratado). Ed. Comisión Europea, Bruselas, 25 de marzo de 1998. 201 págs. Cf. pág. 22.

(9) La controvertida figura de «perro guardián» de la ortodoxia presupuestaria del ya cesado profesor BAREA simboliza muy bien la contradicción permanente a la que se ve sometido un gobierno que presume de su capacidad para sanear las cuentas públicas y a la vez pretende satisfacer las inagotables presiones sociales para disminuir la presión fiscal y aumentar el gasto. 
para la buena evolución de la economía española. Dígase lo mismo del tipo de cambio de la peseta, que se ha mantenido muy estable dentro de los amplios márgenes defluctuación establecidos en el Sistema Monetario Europeo. Aunque no hubiera existido el objetivo de la UM, estos hubieran sido, sin duda, los mejores logros posibles para la política macroeconómica española, junto con el relativamente intenso crecimiento del PIB (a un ritmo del 3,7\%-3,8\% anual en 1998) y la consecuente creación de empleo, a la que aludiremos más adelante.

Como decíamos antes, hace tres años todos, comenzando por el gobierno socialista, hubiéramos firmado este resultado con los ojos cerrados. Ahora bien, tampoco se puede olvidarque el primer y decidido impulso hacia la convergencia, con la elaboración del primer Plan de Convergencia tras la aprobación y ratificación del Tratado de Maastricht, lodio precisamente el gobierno de Felipe González. De alguna manera hay que reconocerle a éste último que el proyecto de la UEM era «su» proyecto, aunque de hecho lograra luego el apoyo de casi todos los partidos, con la excepción de Izquierda Unida, y de casi toda la sociedad española. Sin esa aceptación, los sacrificios de la convergencia no hubieran sido tolerados por la misma.

En efecto, el paralelismo de este proceso hacia la convergencia con el de ingreso de España en la Comunidad Económica Europea es muy aleccionador: ¿cuántas veces no se le recordó al gobierno socialista, y en particular a su presidente Felipe González que, sin la transición política pilotada por Adolfo Suárez y la UCD, sin los Pactos de la Moncloa, cuyo programa económico elaboró un ministro conservador, Enrique Fuentes Quintana, sin las gestiones y negociaciones previas al año 1982, no se hubiera conseguido-como si de una fruta madura se tratase- el gran logro de la adhesión a la CEE el 1 de enero de 1986 ?

Estas últimas consideraciones nos remiten a unas reflexiones más generales que nos interesa destacar: a nuestros partidos políticos les sobra sectarismo y les falta asumir el hecho de que realmente sus grandes logros responden a demandas sociales globales, independientemente del color del gobierno de turno, demandas que los propios partidos se encargan de materializar. Sin negar los méritos concretos e inmediatos de una u otra administración, estamos persuadidos de que el movimiento de fondo es el de una sociedad madura que sabe lo que quiere y acepta el camino que conduce hacia sus objetivos más universalmente asumidos; consideramos por ello ilegítimo cualquier intento de «secuestro», sea 
por parte del PSOE en relación con el proyecto de la adhesión a la CEE, sea por parte del PP en relación con la entrada en la moneda única. Y, como lo cortés no quita lo valiente, reconocemos que, en estos dos campos, cada gobierno desempeñó correctamente la tarea que le correspondió.

Pero, insistimos, la convergencia ha sido posible gracias a todos: no sólo el gobierno ha aplicado un plan razonable de convergencia, sino que el Banco de España se ha acomodado prudentemente a él, las empresas han formado expectativas de que se entraba (al final iba a ser una cuestión política), los sindicatos se han mostrado razonables, la competencia ha funcionado y... llevamos más de doce años de esfuerzos para parecernos a los europeos. En palabras más técnicas, la claridad en los objetivos de política económica y el consenso social que han suscitado, la generación de expectativas positivas (10), la buena coyuntura internacional (petróleo y otras materias primas baratos, crecimiento sostenido no inflacionario en los Estados Unidos, etc.) y el tiempo que llevamos en el empeño han sido, en nuestra opinión, las claves de la convergencia.

\section{Política monetaria y financiera: en el nuevo marco de la Unión Monetaria}

Si la política presupuestaria (11) ha sido decisiva para el cumplimiento de las condiciones de convergencia, no menor ha sido la importancia de la política monetaria y financiera. Por eso la abordamos a continuación.

Hay que comenzar recordando que la Ley de autonomía del Banco de España de 1994 concedía a esta institución la responsabilidad plena en el diseño y ejecución de la política monetaria(12). Yaunque sus buenos resultados no pueden

(10) ...aquello de Virgilio: «hos succesus alit: possunt quia posse videntur» (Eneida, Libro $5^{\circ}$ ), o sea, que los que triunfan son precisamente aquellos que son capaces porque creen poder serlo...

(11) El proyecto de presupuesto del99, calificado por algunos comentaristas como «el más cómodo de Rato», (Cf. Cinco Días, 30 de septiembre de 1998, p. 22) prevé un déficit de las Administraciones públicas totales del 1,6\% sobre el PIB, con un crecimiento esperado del PIB del 3,8\% sobre 1988 y una previsión de inflación del 1,8\%.

(12) LuIs ANGEL RoJo ha sido una figura discreta e indiscutida al frente del Banco de España, loque no le ocurrió por cierto a alguno de sus predecesores; aunque independiente del gobierno, ha sido un actor decisivo en la política de convergencia nominal. 
atribuirse al gobierno actual, sino al banco emisor, es imprescindible aludir en este momento a ella.

Durante estos dos años la política monetaria ha estado marcada por el rigor, con el fin de lograr una reducción paulatina de la inflación. Las condiciones exteriores e interiores han contribuido a alcanzar dicho objetivo, permitiendo además una reducción progresiva y sustancial del tipo de intervención decenal (el llamado precio oficial del dinero) (13). Como resultado, las tasas de interés han bajado también en los mercados financieros de forma paralela. Del gobierno lo que puede decirse es que ha actuado en franca sintonía con esta política del Banco de España. En efecto, sus medidas económicas y presupuestarias de estos años han apostado claramente por la estabilidad, como el camino más adecuado para lograr el objetivo de la convergencia.

La política financiera sí es, en cambio, competencia del gobierno. Cuando inició su mandato - al comienzo de 1996- se encontró con que los mercados financieros estaban condicionados por dos aspectos estructurales importantes: un alto grado de liberalización, resultado del proceso iniciado en los años setenta; y la preparación de la tercera fase de la UM, a la que probablemente podría incorporarse España. Estos dos rasgos limitaban fuertemente la posibilidad de realizar una política financiera de nuevo cuño y hacían casi inevitable el continuismo.

Así fue efectivamente. Si observamos las medidas de política financiera adoptadas desde el comienzo del gobierno del Partido Popular, encontramos que las decisiones de cierto calado están relacionadas con los dos aspectos citados:

- Medidas liberalizadoras relacionadas con los mercados en los que aún existían algunas limitaciones: control de divisas e inversiones extranjeras. Ambos mercados están, por otra parte, ligados con el fenómeno de la globalización de los mercados y con la creación del mercado único financiero en el ámbito comunitario.

- Incorporación de las directivas comunitarias a la legislación española. En este terreno destaca la normativa sobre sociedades y agencias de valores, que liberalizará profundamente los mercados de valores, sobre todo la

(13) Recientemente, a primeros de noviembre de 1998, las subastas han pasado a ser semanales, para acompasar el ritmo español al del Banco Central Europeo. 
bolsa. También es importante el tratamiento de la cobertura de riesgos y del coeficiente de solvencia, política que tiene un importante protagonismo en los mercados liberalizados y de amplitud internacional.

- Decisiones preparatorias de la incorporación a la Unión Monetaria. Por ejemplo: reformas del Sistema Nacional de Compensación Electrónica, del Servicio Teléfonico del Mercado de Dinero y otras medidas relacionadas directamente con la sustitución de la peseta por el euro.

- Desarrollo de la autonomía del Banco de España y cesión de funciones del banco emisor español al Banco Central Europeo, a partir del 1 de enero de 1999: ambas en la misma línea anterior.

- Ciertos cambios en relación con las emisiones de deuda pública (emisiones a 30 años, emisiones en ecus, creación de «strips» (14) de deuda), que se han iniciado con la intención de adaptar los valores públicos españoles a los requerimientos de los mercados europeos, dada la sustitución (parcial) prevista de los mercados nacionales de deuda por los de ámbito europeo.

En otro aspecto de política financiera hubiera sido posible iniciar un cambio de rumbo: el tratamiento de la inversión financiera del ahorro. Pero aquí las novedades han sido poco sustanciales: se ha modificado el tratamiento fiscal, pero se han mantenido las ventajas a favor de las participaciones en fondos de inversión (FIM), al tiempo que se han adoptado otras medidas para facilitar la operativa de estos fondos (15). Esta situación resulta discriminatoria a favor de los FIM, y crea dificultades a la financiación de la empresa y al propio funcionamiento del sistema bancario. El gobierno tenía dos posibles respuestas a esta situación: a) ampliar las ventajas fiscales a otros instrumentos financieros (alguna decisión se ha adoptado sobre los depósitos bancarios, pero de escasa importancia); b) eliminar dichas ventajas fiscales, lo cual probablemente habría afectado negativamente al ahorro familiar. Dadas las dificultades que plantea cualquiera de estas dos decisiones, se ha optado por el camino más fácil:

(14) Como es sabido, el «strip» de deuda consiste en la división de la deuda pública en dos valores: a) nominal sin derecho a intereses; $\mathrm{y}$ b) derecho a los intereses de la citada deuda. Ambos «valores» pueden ser objeto de negociación separada en los mercados.

(15) El atractivo de los FIM viene también determinado por su comportamiento en los mercados de valores, aspecto sobre el cual la política económica tiene, en la actualidad, escaso campo de actuación. 
mantener con algunos retoques la política anterior.

En resumen, en el terreno de la política monetaria y financiera, el gobierno del PP ha hecho una doble elección: por un lado, continuar la política realizada por gobiernos anteriores; $y$, por otro, dedicar la mayor parte de sus esfuerzos al cumplimiento de las condiciones para acceder a la UM. Como aludiremos en relación con otros aspectos, la competitividad en el mercado únicofinanciero depende de las políticas empresariales, sobre todo la de los intermediarios financieros, pero ello no significa minimizar la importancia de la política del gobierno; y juzgamos que en su actuación ha estado demasiado preocupado por el corto plazo, y ha ignorado en gran parte los temas de largo alcance, el futuro marco en el que se va a mover el sistema financiero español.

\section{Política de empleo y de concertación social: menos paro y más diálogo}

La indudable bonanza macroeconómica esbozada más arriba, fruto por supuesto de la política económica del gobierno, pero también de la buena coyuntura económica internacional, se está manifestando con cierta fuerza en la evolución del problema número uno de la sociedad española, el desempleo. Dentro de la gravedad de la situación, los datos estadísticos recientes parecen indicar una cierta mejoría. El 40\% de todo el empleo creado en la UE en los dos últimos años se ha estado creando en España, lo que significa que es éste el país que más empleo crea en la UE. En dos años nuestra tasa de paro, según la Encuesta de Población Activa, ha bajado de algo más del $22 \%$ a algo menos del 19\%. De mayo de 1997 a mayo de 1998 se crearon 415.200 empleos netos, de los cuales, sin embargo, sólo un $8 \%$ son contratos por tiempo indefinido, tasa esta última que, a pesar de todo, duplica a la que existía antes de la reforma laboral de abril de 1997.

Pero esas cifras no son, sin embargo, suficientes para echar las campanas al vuelo, porque no deja de ser grave que nuestra tasa de paro del $19 \%$ casi duplique todavía la media de desempleo de la UE. Es cierto que en España la tasa de actividad crece más que en la mayoría de los países europeos, un fenómeno que se observa sobre todo en Andalucía, precisamente la Comunidad Autónoma con mayor índice de desempleo. Pero todo esto no es sino un motivo más para insistir con renovada eficacia, como piden los sindicatos, en la creación de empleo, procurando que la bonanza y la estabilidad económica 
general se traduzcan en una mayor rebaja de las actuales cifras de paro.

Porque, si el empleo constituye el mayor reto de la sociedad europea, ¿cuanto más para la española? Como bien expresa el flamante premio Nobel de Economía 1998, Amartya SEN: "...el precio que se paga por el desempleo es ingente, y reducirlo ayudaría a resolver muchos de los males sociales de Europa» (16). Y el Tratado de Amsterdam, que por cierto está pasando demasiado inadvertido, coloca por primera vez el empleo en la agenda de la Unión al más alto nivel jurídico. Puede decirse que, si el Tratado de Maastricht hizo de la unión monetaria el gran proyecto europeo, el de Amsterdam incorpora a éste el empleo (17). También la Cumbre de Luxemburgo de finales de 1997, monográficamente dedicada al empleo, marcó un hito en la agenda europea, sin duda debido a las presiones de los nuevos gobiernos socialdemócratas en Gran Bretaña y Francia. ¡Ojalá que esa «ola socialdemócrata», que parece extenderse por la UE, otorgue una decidida prioridad a este grave problema!

En relación con el paro es frecuente contraponer el modelo europeo y el norteamericano. Muchos alaban el segundo porque en él es mucho menor el indice de desempleo, pero suelen olvidar que la menor tas a de paro no se traduce en una distribución más equitativa de la renta (18). En todo caso, no cabe duda

(16) Amartya Sen (1997).- «Desigualdad y desempleo en la Europa contemporánea». Revista Internacional del Trabajo. Volumen 116, nº 2, verano 1997, pp. 169-188.

(17) No hay precedentes en los Tratados fundacionales ni en los siguientes. Véase el excelente comentario de Francisco AldECOALUZARRAGA. - «El Tratado de Amsterdam, un pequeño gran paso en la consolidación del modelo de la Unión».-En Cuadernos Europeos de Deusto, $\mathrm{n}^{\circ}, 18$, 1998, pp. 11-47. Como indica acertadamente el profesor AlDECOA, al Tratado de Amsterdam le faltó poner plazos, objetivos, cuantificaciones, al objetivo empleo; cosa que sí hizo el Tratado de Maastricht con la unión monetaria. Ése es el reto del momento, en una Unión Europea de mayoría abrumadora socialdemócrata.

(18) Aunque con frecuencia se manejan en este debate los argumentos de forma sesgada. Véanse algunos comentarios críticos al modelo USA de ViCENÇ NAVARRO(1997).-Neoliberalismo y Estado del bienestar. Ed. Ariel Sociedad Económica. Barcelona, 221 págs. Véase también: Luis de Sebastián (1998).- «La pobreza en USA». Cuadernos CJ, nº 85, Ed. Cristianismeijustícia, Barcelona. La comparación entre el modelodecrecimiento americanoy el de los países europeos debe hacerse con cuidado para no incurrir en falsas comparaciones; ¿cómo comparar una economía tan bien dotada de materias primas, tan capitalizadafísica y humanamente, tan estable en su sistema político, con un conglomerado tan extenso, variado e inestable de pequeños países como ha sido Europa en el siglo XX? La economía americana ha logrado unas 
que el paro es el tendón de Aquiles del modelo europeo, y que, mientras no se le encuentran vías de efectiva solución, la superioridad del modelo de capitalismo renano sobre el sajón estará siempre en entredicho (19).

Volviendo al caso español, hay que destacar que la acción del gobierno en este terreno ha sido tan indecisa como poco ambiciosa. Tiene que atender a las presiones insistentes del «ala dura» del empresariado que le exige una política de flexibilización laboral radical (20), pero sus dependencias políticas le impiden llegar tan lejos. En la Cumbre de Luxemburgo, por ejemplo, ni siquiera se atrevió a firmar los compromisos concretos que se impusieron todos los países de la UE, alegando que tenían para nosotros un coste inasumible. Unos meses después - en la Cumbre de Cardiff, junio de 1998- presentó su Plan Nacional de Acción por el Empleo, que puede ser calificado, sin embargo, de positivo. Cabe desear que sea puesto en práctica, no sólo con decisión y voluntad política, sino además, en diálogo constante con los agentes económicos y sociales (21).

Muestra también de esta escasa voluntad política puede considerarse el dato que aporta el informe de la OCDE «Perspectivas del empleo 1998»: España dedicó solamente un 0,5\% del PIB a políticas activas de empleo en 1997, mientras que dos años antes el porcentaje fue del 0,81\%. La cuestión es más

altas cotas de productividad y eficacia gracias a algunos factores que en Europa vamos buscando y que ellos tienen desde hace tiempo: un mercado amplio, único y protegido, una moneda única, un mercado de trabajo homogéneo, un sistema político estable, una política exterior común. Es de esperar que los europeos alcancemos esa cotas de productividad y renta, pero nos gustaría lograrlo con más justicia en el reparto y con más ética en los instrumentos empleados...

(19) Cf. Albert, Michel (1993).- Capitalismo contra capitalismo. Edita Paidós, Barcelona.

(20) Postura materializada en textos tales como: Rafael Termes CARrero (Dir.) (1996).Libro blanco sobre el papel del Estado en la economía española. Madrid, Ed. Instituto Superior de Estudios Empresariales. El capítulo8 de esta denominada «Biblia» del neoliberalismo español, con pretensiones cuasi-teológicas, se titula «Reforma del mercado de trabajo» y defiende-en línea con todo el documento-posiciones radicales en pro de la flexibilización, de la disminución del Estado del bienestar y de la desprotección social.

(21) Para una descripción y una valoración más detallada de este Plan remitimos al comentario de nuestro habitual colaborador JAVIER GorosQuiETA.- «El Plan Nacional de Acción por el Empleo». Razón y Fe, junio 1998, pp.623-630. Ahí se habla también, en particular, del actual debate en torno a la jornada de 35 horas semanales, y de la necesidad de mejorar, a pesar de todo, la política pasiva de protección contra el desempleo. 
compleja de lo que parece a primera vista: porque ¿no es contradictorio que el año en que nuestra economía más convirtió crecimiento en empleo, 1997, sea el de menor gasto en políticas activas de empleo? ¿no será que lo determinante para luchar eficazmente contra el paro sea más la calidad de las políticas emprendidas que la cantidad de los fondos comprometidos?

Esta indecisión y falta de orientaciones claras se manifiesta también en el caso del debate en curso sobre el reparto del tiempo del trabajo, al que nos referimos extensamente en nuestro anterior editorial (22). El PP se niega sistemáticamente (23) hasta a entrar en él, en abierto contraste con las tendencias europeas más progresistas. Porque es difícil ignorar que la dinámica europea conduce inexorablemente a tomar parte en dicho debate.

En todo caso, parece necesario y urgente acometer políticas más creativas de promoción de empleo. Como ha escrito acertadamente -y con algo de optimismo- IGNACIO SOTELo:

«...enfrentarse al problema del paro implica en buena parte prestar oídos sordos a los consejos de los economistas y tomar decisiones poco convencionales, que ya llegarán» (24).

A pesar de todas estas limitaciones, la imagen del gobierno en este aspecto es relativamente buena. Sin duda ha sido reforzada por la política y la praxis del diálogo social. Aunque los dos actuales sindicatos más representativos son formalmente de izquierda, el gobierno del PP han entablado con ellos un diálogo mucho más fluido y fructífero que el que mantuvieron con los gobiernos del PSOE, los cuales llegaron incluso a tener que soportar dos huelgas generales. El talante dialogante y negociador de JAVIER ARENAS -y su equipo-desde el Ministerio de Trabajo ha facilitado sin duda las cosas. Fruto principal de ese diálogo fue la Reforma para la Estabilidad en el Empleo, firmada en abril de

(22) Consejo de Redacción.- «El reparto del tiempo de trabajo». Revista de Fomento Social, no 210, abril-junio 1998, p. 153-176.

(23)AzNAR llegó a calificarlo de «estupidez» (como ModiGLIANI, por cierto; ...y al contrario que KEYNES) para luego criticarlo en razón de sus costes, sin entrar en el fondo de un problema complejo que tiene muchas caras y al que no se puede liquidar de un plumazo.

(24) Ignacio Sotelo.- «Primacía de lo político». El País, 3 de abril de 1998, pág. 10. 
1997 por gobierno, patronal, Comisiones Obreras y la Unión General de Trabajadores. Esta reforma parece estar dando resultados significativos, en particular en el incremento de la tasa de contratos fijos, al que aludimos más arriba. La técnica del «diálogo hasta la extenuación» (en palabras del ministro ARENAS) se quiere extender al Plan Nacional de Acción por el Empleo y al tema ahora estrella de la reducción de la jornada laboral. Creemos que es ésta una línea de acción que conviene, a toda costa, mantener, sea cual sea la ideología del gobierno.

En términos numéricos, se puede considerar como un resultado particular de esta política la disminución de las huelgas: pasaron de 866 en 1995 a 520 en 1997; por su parte los 570.000 participantes en 1996 cayeron hasta 330.000 en 1997. Es indudable que existen condiciones objetivas favorecedoras de este diálogo (como son las dificultades económicas de los sindicatos y su reducido número de afiliados, así como el temor más que comprensible a la pérdida del empleo), pero no cabe olvidar que el marco era casi idéntico cuando el PSOE estaba en el poder y el diálogo fue casi siempre inviable.

Una última manifestación-la más reciente-de esta capacidad de concertación social la constituye el acuerdo entre el gobierno y sindicatos, relativo al trabajo a tiempo parcial, a falta de ratificar por la patronal y que se produce estando ya en prensa este texto. El acuerdo ha estado precedido de una negociación larga, tensa por momentos, pero su culminación es una nueva confirmación de ese talante de diálogo que caracteriza a todos los interlocutores sociales.

\section{Política de bienestar: ¿ «retirada» neoliberal?}

En el actual contexto mundial marcado por el neoliberalismo, se ha venido afirmando durante años que las sociedades no podían ser competitivas si no reducían drásticamente el gasto social, si no disminuían el papel del Estado. Ése es uno de los dogmas del llamado pensamiento único. Como recuerda PETRELLA:

«La solidaridad sobre la que se construyó el Welfare State ya no se considera como el principio de la virtud de las sociedades» (25).

(25) Ricardo Petrella (1997).--El bien común. Elogio de la solidaridad. Ed. Temas de debate, Madrid, p. 15. 
Como indicamos en un editorial de 1993 (26), la mera política macroeconómica de convergencia descrita más arriba hubiera sido muy similar con un gobierno de otro color político.

Es conocido que los «cantos de sirena liberal» presionan ferozmente a escala mundial para que, en concreto, la UE vaya rebajando las actuales prestaciones de sus Estados de Bienestar. A juzgar por algunos datos, y aunque no está libre ni mucho menos de esas tentaciones -como, por cierto, ningún gobierno europeo-no se puede decir sin más que el actual gobierno se haya dejado seducir por tales melodías.

Bajo el concepto de «Estado del Bienestar» se engloban un conjunto de derechos económicos y sociales reconocidos por el Estado a un ciudadano por el mero hecho de serlo. Pero este reconocimiento no prejuzga si la realización de ese derecho es responsabilidad de una organización de titularidad pública o privada (aunque siempre tutelada). Más allá de las discutibles manifestaciones de la ministra de educación, de los cambios amagados en sanidado del ritmo, las formas o los detalles de esas políticas, hay una cuestión de fondo que hoy no se puede eludir: ¿cómo valorar las tendencias privatizadoras en los servicios públicos?

Pensamos que, a priori no hay ninguna razón filosófica, política o económica que garantice que un determinado servicio público habrá de sernecesariamente mejor prestado si lo hace una entidad de titularidad pública que si ésta es privada (27). Dicho en términos económicos y en pocas palabras, mientras la prestación se realice de forma efectiva y satisfactoria a diferencial de coste cero o próximo a cero, da lo mismo quien la haga.

Nuestro análisis al respecto se centrará en los grandes bloques que suelen ser incluidos en las «Políticas de bienestar»: la educación, la sanidad, los sistemas de la protección social y la vivienda. Puede afirmarse - por comenzar ciñéndonos a las cuestiones de fondo-que el gobierno popular ha pretendido-de palabra

(26) Consejo de Redacción (1993).- «La década del gobierno socialista: un balance económico». Revista de Fomento Social, n 190, abril-junio, cf. pp. 184-185. Titulábamos precisamente entonces ese apartado: «Qué queda del modelo socialdemócrata».

(27) Véase a este respecto el interesante trabajo: Nicolás M ${ }^{a}$ LóPEZ CALERA (1998).«Manifiesto público sobre lo público». Revista de Fomento Social, n²09, enero-marzo, pp.111-118. 
y de obra-avanzar en el camino de la privatización.

Empezando por la educación, y aunque sea de pasada, opinamos que el servicio público no es monopolio de la titularidad pública y es fácilmente demostrable que los efectos perversos del sistema pueden hacer que, en determinadas ocasiones, los fondos públicos se utilicen en la enseñanza de titularidad pública -incluida la universitaria-para favorecer intereses privados y que, por el contrario, al igual que existe una cierta enseñanza privada clasista, elitista y sectaria, existe de hecho también una enseñanza de titularidad privada, financiada o no con fondos públicos, que cumple con excelencia un servicio auténticamente público no discriminatorio o incluso de carácter compensatorio con presencia selectiva en zonas rurales y barrios marginados. Pero éste es un debate que seguramente abordaremos en nuestra Revista de Fomento Social en profundidad en otra ocasión.

Concretando más, en este campo de la educación, de hecho se ha mantenido el gasto público en porcentaje del PIB, incrementándose incluso desde el 5,3\% de 1993 al entorno del 6\% en 1997. También aquí habría que analizar con más cuidado esa cifra-lo que desborda las pretensiones de este editorial-ya que la progresiva reducción del territorio educativo del Ministerio propiamente dicho, puede hacerla engañosa. Sin embargo no parece que el diálogo con los protagonistas del sistema educativo, tanto en primaria y secundaria como en la enseñanza universitaria haya sido exitoso. Pero este asunto, más que a la política económica, se refiere al talante político del gobierno.

En materia de sanidad ha habido un indudable recorte: el que está representado por el nuevo «medicamentazo», paralelo - no hay que olvidarloal que realizó el gobierno socialista hace varios años. En principio, en general, no creemos que haya sido un acierto este decreto, menos en lo que tiene de lucha contra el abuso en el suministro de medicinas; parece, sin embargo, una cuestión de fuerza mayor ya que, de lo contrario, «no salen las cuentas»; por otra parte, se mantiene la administración gratuita o a bajo coste para el beneficiario de la Seguridad Social, de los medicamentos esenciales o convenientes; queda por ver si va a suponer un ahorro significativo del gastofarmacéutico, lo que algunos ponen en duda.

También hay que reseñar, además del «medicamentazo», las mejoras en las prestaciones sanitarias del llamado territorio Insalud, medidas por ejemplo, por la reducción de las listas de espera. 
En lo relativo al gasto sanitario, la comparación de las cifras correspondientes con la situación anterior queda relativizada por la transferencia de las competencias sanitarias a Andalucía, Cataluña, Galicia, País Vasco y Navarra, regiones que agrupan un porcentaje importante de población.

Respecto a los sistemas de protección social, el gobierno ha mantenido el poder adquisitivo de las pensiones, e incluso mejorado algo su poder de compra en 1997 al haberse revalorizado a primeros de ese año en un porcentaje superior al de la inflación. Por otra parte, el actual ejecutivo mantiene, en concreto, en la actual política social, los compromisos del Pacto de Toledo que, adicionalmente, ha consensuado con las centrales sindicales más representativas. Ello ha implicado, de hecho, entre otras cosas, una mayor dificultad para el acceso a una pensión a nuevos pensionistas.

Por lo que respecta a la vivienda, se ha elaborado una nueva Ley del Suelo que trata de abaratar la altísima incidencia del precio de los solares, por término medio, entre un $30 \%$ y un 40\%, según los casos, en el precio final de la misma. El porcentaje de la renta media familiar disponible que habría que destinar en España a la compra de una vivienda de precio medio ha pasado, con desgravaciones fiscales, del 32,2\% en 1996 al 26\% en 1998. Este descenso se debe, desde luego, a la bajada del precio del suelo inducida por los cambios legales indicados en sentido liberalizador, pero también al hecho de que la bajada de los tipos de interés de los préstamos hipotecarios y el cambio en la ley de subrogación de las hipotecas han provocado una disminución sensible de los costes de financiación de la vivienda (28).

A la luz de los datos anteriores, la cosa no debe estartan clara, cuando muchos critican y califican la Política de Bienestar del gobierno Aznar como «una retirada ordenada». Por ejemplo, según el PSOE (29), el gobierno popular ha descuidado entre otras cosas la atención al sistema educativo público en beneficio-indebidamente-de la enseñanza privada. En relación con la sanidad, se acusa al gobierno de hacer una gestión «orientada a cuestionar el sistema

(28) La ley del suelo ha contentado a los ayuntamientos porque les está dando una mayor «alegría» constructora, pero no ha sido todo lo liberal que se esperaba porque el PP no se ha atrevido a poner una penalización a los solares inutilizados, loque hubiera desamortizado una parte importante del suelo urbano en no pocas ciudades.

(29) Cf. Grupo Parlamentario Socialista, op. cit. 
público» y a «privatizary cobrar prestaciones sanitarias gratuitas». Por último, en lo que respecta al sistema de protección social, los socialistas afirman que se ha procedido a «un recorte y eliminación de derechos adquiridos por determinados colectivos», subrayando por otro lado paradójicamente el «deterioro financiero de las cuentas de la Seguridad Social». Ésta ha tenido ahorro corriente negativo (déficit corriente) desde 1991. El máximo (casi 300.000 millones de pesetas) se alcanzó en 1996; en 1997 bajó a 100.000 millones. Las necesidades de recursos financieros fueron mucho mayores: unos 900.000 millones en 1996 y 800.000 millones en 1997.

Sin embargo, no pensamos que Aznar haya desarrollado en las políticas de bienestar la propia de una «derecha pura y dura», y ello por estrictas razones «de gobernabilidad». La rentabilidad de una política tan conservadora hubiera sido muy escasa, ... y Convergencia i Unióno se lo hubiera permitido. Dicho en clave política: si consideramos que las Comunidades Autónomas, especialmente las dos más grandes (Andalucía y Cataluña), son gestoras de importantes volúmenes de fondos destinados a los "gastos de bienestar», ya que tienen transferencias en sanidad, educación, etc., y que ambas están gobernadas por otros partidos, nos encontramos con que un recorte significativo del gasto público en estas políticas (eso sería una política «de derecha pura y dura») resulta prácticamente imposible.

A Cataluña no se le puede recortar porque la legitimación de la Generalitat depende de su capacidad de proveer de servicios (con una cierta contradicción ideológica del partido de Pujol, dicho sea de paso) y, por lo tanto de gasto, y los votos de CiU son la clave de la gobernabilidad del Estado. Y a Andalucía sólo se le puede recortar «arteramente» (por ejemplo, no reconociendo el censo real) pero no explícitamente: las esperanzas de la mayoría absoluta pasan para el PP por un aumento de votos en Andalucía.

Por tanto el gobierno Aznar no ha atacado como hubiera sido de esperar (...o, mejor dicho, de temer) las políticas de gasto público de bienestar por razones tácticas más que por convicción (30), y ha presentado a la ciudadanía lo

(30) En palabras de IGnAcio Sotelo: «Una economía que funciona mejor sin haber por ello desmontado el Estado social...». En «La segunda transición», El País, 27 de octubre de 1998. Desmontaje mayor por el que luchan los más duros de la corriente neoliberal citada más arriba. Cf. Termes, op.cit. 
realizado como un giro al centro, lo que es - al fin y al cabo- una buena forma de rentabilizar políticamente esa misma imposibilidad. Es, como se suele decir, «hacer de la necesidad virtud». Y, seguramente, es también una de las grandes ventajas de la ausencia de mayoría absoluta...

\section{Política tributaria: neutralidad y gobernabilidad o equidad y solidaridad}

Es éste un ámbito de especial relevancia, ante todo por su importancia intrínseca para la política económica, pero también porque se maneja como bandera ideológica definitoria de los objetivos de tirios y troyanos... El ser éste uno de los campos de acción de política económica en que el PP parece haber definido una política propia nos obliga a detenernos algo más en su análisis.

Bajar la carga impositiva era uno de los compromisos electorales más claros de los populares. Y para ello tropezaban con un obstáculo de envergadura: la necesidad de reducir drásticamente el déficit público en virtud de los compromisos del Tratado de Maastricht. Pero la fortuna -bajo la forma de coyuntura favorable - ha ayudado sin duda a los populares (31): en efecto, la relativa recuperación económica ha contribuido a incrementar los ingresos públicos y a disminuir los gastos; por otro lado, la notable bajada de los tipos de interés ha reducido considerablemente el servicio de la deuda, como se sabe una de las partidas más onerosas del conjunto del gasto público.

Entre las medidas tributarias adoptadas en lo que va de legislatura, cabe destacar sobre todo el incuestionable apoyo que se ha venido dando a las PYMES, a las que se considera uno de los principales motores para el crecimiento económico y la generación y mantenimiento del empleo. Aunque esta política y a se inició durante el gobierno del Partido Socialista, ahora se avanza de forma mucho más firme y decidida. Entre las medidas más destacadas se encuentran:

- la mayor flexibilización en los requisitos a cumplir para gozar de la exención de las denominadas «empresas familiares» en el Impuesto sobre el Patrimonio;

- la «exención» prácticamente total en el Impuesto sobre Sucesiones y

(31) Como también en su día, por cierto, a los socialistas. Titulábamos el apartado dedicado a esa reflexión en el editorial citado anteriormente: «El espejismo de la recuperación de 19861990: los vientos de la fortuna». Cf. Consejo de REDACCIÓn, op. cit., p. 181. 
Donaciones ( se establece una reducción del 95\%) de la adquisición de este tipo de empresas;

- la reducción en un $15 \%$ del rendimiento neto en el régimen de módulos para los años 1996 y 1997 (lo que se produce en un contexto de expansión económica en el que los rendimientos empresariales han crecido de manera notable);

- la reforma en 1998 de los regímenes de determinación de la base imponible en el Impuesto sobre la Renta de las Personas Físicas (pretende adecuar la tributación de las PYMES a la realidad económica de estas entidades);

- y el establecimiento en el Impuesto sobre Sociedades para las empresas de reducida dimensión de un tipo de gravamen del 30\% (en lugar del 35\%) para la parte de base imponible que no supere los 15 millones.

Son de destacar también aquellas medidas que han intentado un mejor «ajuste» del sistema tributario a la realidad económica de las empresas. Tal es el caso de la posibilidad, tan anhelada por nuestro sector empresarial desde la última vez que se permitió en 1983, de actualizar los balances de las sociedades españolas, atenuando así los perniciosos efectos de la inflación. En esta misma línea hay que incluir la normativa encaminada a eliminar o atenuar en el Impuesto sobre Sociedades los siempre perturbadores fenómenos de doble imposición (tanto interna como internacional).

Dado que una de las promesas electorales del Partido Popular era la rebaja de la presión fiscal, resultará paradójica la creación en 1997 de un nuevo Impuesto sobre las Primas de Seguros, así como de numerosas tasas de nuevo cuñoy la elevación de las ya existentes. Quizás no está de más recordar que según datos de la Oficina Estadística Europea (Eurostat) la presión fiscal española -impuestos más cotizaciones sociales- se elevó durante el ejercicio 1997 del 35,6\% al 36,2\% del Producto Interior Bruto. Esta tendencia al aumento de la presión fiscal se modificará sustancialmente hasta cambiar de signo con el nuevo Impuesto sobre la Renta de las Personas Físicas (32) que, en el momento

(32) Véase el trabajo de nuestro colaborador: JAVIER GorosQUIETA (1998).- «La nueva reforma del IRPF». Revista de Fomento Social, no , 210, pp. 285-294. También han escrito sobre el mismo tema, con mayor carga crítica, nuestros colaboradores ILDEFONSO CAMACHO, Julio JiMÉnEZ (1998), «La reforma del Impuesto sobre la Renta: ¿por la eficiencia o por la equidad?». En Iglesia Viva, n 195, julio-septiembre. 
de escribir estas líneas, se tramita en el Parlamento.

Es de alabar de la reforma del IRPF que se avecina la importante simplificación que se va a producir en el tributo, la adecuación del importe de las retenciones con la cuota a pagar, la consideración más ajustada de los gastos reales del contribuyente para atender a sus necesidades básicas y a las de su familia, etc. Sin embargo da la impresión de que se ha sacrificado con relativa ligereza la equidad en favor de la eficiencia económica (entendida en términos de neutralidad del impuesto en un mercado competitivo), aun cuando la incidencia en ésta última de las modificaciones introducidas es, en ocasiones, más que discutible (eso ocurre por ejemplo con la reducción del número de tramos de la tarifa del impuesto). También atenta contra la progresividad del tributo el traslado que se ha hecho de numerosas deducciones de la cuota a la base, con el consiguiente establecimiento de un denominado mínimo personal y familiar. Asimismo resulta discutible el tratamiento que se da a las ganancias y pérdidas patrimoniales (una fuente cuantiosa de las rentas del capital), mucho más beneficioso que el que corresponde a las rentas del trabajo.

A propósito de la reforma del IRPF en curso y de las otras modificaciones mencionadas en materia impositiva, conviene todavía recordar que en todo sistema tributario es importante no sólo cuánto se recauda, sino cómo se recauda. Aunque está previsto que la pérdida de recaudación por la rebaja del Impuesto se recupere por otras vías (descubrimiento de deuda tributaria no declarada, incremento en la recaudación por una mayor actividady crecimiento económico, ahorro en los costes de gestión del tributo), es más que probable que el nuevo IRPF sea un impuesto menos progresivo, y que por su menor peso cuantitativo en el volumen de la recaudación tributaria total, también sea menor la progresividad global del sistema tributario. No debe olvidarse que la progresividad impositiva es un precepto del art. 31 de nuestra Constitución, y que aquélla está al servicio de la efectiva igualdad: el mismo esfuerzo o sacrificio a la hora de contribuir.

Un último objetivo ha guiado la política tributaria del PP: mejorar la imagen de la Hacienda Pública española. En este sentido se han ampliado y mejorado los servicios que se ofrecen al ciudadano para facilitarles el cumplimiento de sus obligaciones fiscales, al tiempo que se ha aprobado el llamado Estatuto del contribuyente que recoge muchas normas preexistentes pero introduce también algunas mejoras significativas. El citado Estatuto otorga una mayor seguridad 
jurídica al ciudadano, aunque algunos lo han calificado de excesivamente desequilibrado en favor del contribuyente.

En otros temas el gobierno del Partido Popular ha venido a hacer realidad, al menos en parte, las aspiraciones de otros grupos políticos. De alguna forma esto es lo que acontecido con el peliagudo tema de la financiación autonómica. Este tema, que afecta gravemente al modelo mismo de Estado, ha estado totalmente condicionado por la necesidad del gobierno de contar con el apoyo nacionalista en el Parlamento. Sin entrar a analizar en profundidad este asunto, parece indudable que ha primado sustancialmente el principio constitucional de autonomía financiera, quedando muy en segundo término otros principios tan importantes como son el de coordinación y el de solidaridad interterritorial. Es más, resulta duro aceptar que la urgencia de apoyo político obligue a tomar decisiones que condicionan el futuro porque nos introducen en caminos que tienen muy difícil marcha atrás.

Aparte de consideraciones estrictamente políticas, la actitud reivindicativa y conflictiva de los tres únicos gobiernos autonómicos socialistas (Andalucía, Extremadura, Castilla-LaMancha: precisamente tres de las regiones españolas menos ricas) tiene sin duda algún fundamento en la preocupación por evitar un trato económico discriminatorio por parte del gobierno central aliado con los nacionalistas. Cabría concluir que la cohesión territorial es un tema casi abandonado por el PP, como ya lo había sido en la práctica por los gobiernos socialistas anteriores. Esto significa que las políticas de reequilibrio territorial van a quedar casi exclusivamente en manos de la UE (en una aplicación «al revés» del principio de subsidiariedad), cosa poco esperanzadora si se tiene en cuenta la pretensión de los países ricos de disminuir su aportación a las arcas comunitarias y las mayores exigencias derivadas de la ampliación de la UE hacia el Este.

\section{La política de privatizaciones: ¿ideología, pragmatismo o necesidad de liquidez?}

«Privatizar»y «liberalizar» han sido sin duda dos de las palabras más recurrentes en el lenguaje de la política económica del gobierno popular, antes y después de las elecciones. Si se analizan las medidas tomadas por los Consejos de Ministros del gobierno AzNAR, un número muy elevado de iniciativas 
gubernamentales han conjugado precisamente esos dos verbos durante estos dos años y medio.

Conviene recordar que fue el gobierno socialista quien, con la privatización en el punto de mira, procedió en julio de 1995 a una reestructuración radical del sector público empresarial industrial, con la práctica desaparición del INI y el INH; se procedió a agrupar el conjunto en dos grandes grupos: en SEPI (Sociedad estatal de participaciones industriales, denominada TENEO hasta 1996) se incluyeron las empresas industriales del antiguo INI rentables, susceptibles de ser enajenadas con buenas perspectivas de generar ingresos; el segundo grupo, la AIE (Agencia industrial del Estado), quedó constituido por empresas insuperablemente deficitarias sometidas a procesos de reconversión, como la minería, algunas siderúrgicas y navales, difícilmente enajenables por su carácter subvencionado. El otro gran bloque de empresas públicas, las de la Dirección General del Patrimonio, también se han visto sometidas a un proceso intenso de privatización. Hemos de insistir, por lo tanto, en que la política de privatizaciones la inició el gobierno anterior.

Hay aquí un factor ideológico importante. La tradicional política de izquierdas defiende en general un sector público de grandes dimensiones y, más en concreto, un extenso y estratégico sector público empresarial. La política tradicional de derechas sostiene, más bien, la privatización masiva de las empresas públicas. No cabe duda que en nuestro tiempo los vientos soplan masivamente en esta segunda dirección y que ni siquiera los gobiernos socialdemócratas están por la labor de recomponer un fuerte sector público empresarial, sino todo lo contrario. Como dice RICARDo PETRELLA, es éste uno de los mandamientos de las nuevas «tablas de la ley»: «eliminarás cualquier forma de propiedad pública y de servicios públicos. Dejarás el gobierno de la sociedad a la empresa privada» (33).

Sin duda, en este debate vale la observación de TONY BLAIR de que más que de política ideológica de derecha o de izquierda conviene hablar, pragmáticamente, de política acertada o desacertada.

Pero hay que añadir a esas argumentaciones ideológicas, la urgencia de sanear las cuentas públicas, en particular de rebajar el montante de la deuda

(33) Ricardo Petrella, op. cit. p. 75. 
pública; como otros gobiernos europeos, y no precisamente conservadores, el gobierno español tanto del PSOE como del PP encontraron en la venta de las acciones u obligaciones del patrimonio empresarial público una fuente de saneados-pero excepcionales-ingresos con que rebajar una deuda pública viva que superaba con creces la regla establecida por el Tratado de Maastricht para aprobar el examen de convergencia (34). Queda por ver si este saneamiento excepcional de las cuentas públicas será sostenible cuando desaparezcan estos ingresos totalmente atípicos.

El gobierno del PP, como antes lo hizo el PSOE olvidándose de sus etiquetas formales, ha apostado claramente por la privatización de lo que iba quedando de empresa pública en España. En conjunto, acertadamente, porvarias razones: porque, en general, la empresa privada es mejor gestionada que la pública; porque frecuentemente para la gestión de la empresa pública se nombran directivos no tanto por su competencia y preparación para la gestión cuanto por su adscripción y relieve político; porque conviene, en principio, exponer a las empresas públicas a la saludable competencia en los mercados, sin darles el seguro de vida del recurso, en caso de pérdida, a «la pólvora del rey», a la sangría de los recursos del presupuesto público.

Nadie, o casi nadie, discute ya la política de privatizaciones llevada a la práctica por el gobierno del PP. Es significativo que, en el citado documento, el PSOE se queje simplemente de que los fondos así recuperados no se utilicen para desarrollar políticas activas de empleo. Sólo quedarán en el sector público Hunosa, por la fuerza mayor de la falta, por el momento, de alternativas laborales para su numerosa plantilla y, seguramente, alguna otra por razones de seguridad nacional, como pueden ser algunas fábricas de armamento y de aviones de combate.

Bien es verdad que la gestión privada no garantiza por sí sola, como por milagro, la buena gestión y el servicio al bien común...

(34) Según datos publicados en la prensa, los ingresos por privatizaciones de empresas pertenecientes a la Sociedad Estatal de Participaciones Industriales (SEPI) ascienden a: 176.000 millones de pesetas en 1996; 1,06 billones en 1997; 1,67 billones en 1998; y se espera ingresar en 1999588.000 millones de pesetas. Cf. El País, 2 de noviembre de 1998, p. 70. 


\section{Algunos costes de la convergencia: «políticas cenicienta»}

Para empezar, señalamos entre las políticas «abandonadas», las de infraestructuras y de I+D porque son asignaturas pendientes en el gobierno del PP. No es propio de humanos el hacer milagros, y si se ha sostenido básicamente el Estado del bienestar y si, al mismo tiempo, se ha logrado la convergencia en materia de déficit público, es también porque se han resentido las políticas de infraestructuras y las inversiones públicas en Investigación y Desarrollo. Así, si en 1996 se invirtieron en infraestructuras 1,76 billones de pesetas (el 2,4\% del PIB), en los tres primeros trimestres de 1997 esa inversión había bajado a 0,64 billones (el 1,67\% del PIB).

Por ejemplo, el 7 de julio de 1998, la Asociación Española de Carreteras señalaba que las carreteras españolas están ahora peor que hace diezaños y que, para una adecuada conservación, sería necesario invertir 408.000 millones de pesetas, lo que supondría quintuplicar los fondos que en la actualidad destina el gobierno a mejorar el pavimento.

Asimismo, las inversiones públicas en Investigación y Desarrollo fueron en 1997 inferiores a los 590.688 millones de pesetas (el 0,92\% del PIB) empleados en 1996. Y este capítulo es esencial para el desarrollo y el bienestar de la sociedad española a largo plazo. No podemos vivir sólo de las royalties si queremos situarnos y mantenernos en posiciones de vanguardia.

Por otro lado, desde la perspectiva de nuestra Revista no basta con preguntarse si la economía española «va tan bien» como pretende el gobierno; hay que ir más lejos: la pregunta que hay que hacerse al llegar aquí es la siguiente: ¿es la sociedad española más justa, más igualitaria, más solidaria? No parece que este gobierno se distinga por tener una política explícita y específica contra la pobreza. Según un muy reciente estudio elaborado en el entorno de Cáritas y patrocinado por la Fundación FOESSA (35) hay actualmente en España 8.509.000 pobres, entendiendo como tales a las personas que viven con menos de la mitad de los ingresos medios por habitante de nuestro país. Hemos empeorado relativamente respecto de aquella famosa cifra de 8 millones de pobres que arrojó aquel otro estudio de Cáritas de 1984. El $25 \%$ de los pobres

(35) EDIS Y VARIOS.-Las condiciones de vida de la población pobre en España. Informe general. Fundación FOESSA. Madrid, 1998. 750 págs. 
se encuentran hoy en Andalucía. En general se concentran en el Centro-Sur (Andalucía, Extremadura, Castilla La-Mancha) y en la frontera con Portugal. Sin embargo, no vamos a entrar aquí a analizar el problema de la pobreza, lo que ya hicimos en un editorial anterior (36).

Habría también que referirse aquí a la falta de una clara política de solidaridad y compensación interterritorial; pero ya hicimos mención de ello más arriba.

Porúltimo, no podemos dejar de mencionar que también los fondos destinados a la política de cooperación al desarrollo han sufrido un ritmo descendente bajo el gobierno popular, siguiendo por cierto la misma tendencia de los últimos años de gobierno socialista (0,28\% en 1993; 0,27\% en 1994; 0,24\% en 1995; 0,22\% en 1996; 0,23\% en 1997) (37). En descargo del gobierno hay que decir, desgraciadamente, que esta tacañería para con los fondos de ayuda al desarrollo parece generalizarse en la mayoría de los países de la OCDE... Pero, por otro lado, cuestionamos la propia filosofía del gobierno en esta materia, tal como ha quedado plasmada en la Ley de Cooperación que tiene muchos aspectos sumamente criticables (38).

(36) Cf. Consejo de Redacción (1996).- «El reto de la pobreza». Revista de Fomento Social, no 203, julio-septiembre, pp. 297-318.

(37) Véase el reciente informe de INTERMón (1998).- La realidad de la ayuda 1998/99. Ed. Intermón, Madrid, cf. p. 17. Pese a la ligera subida (1 centésima) de 1997 seguimos siendo los cuartos donantes por la cola de los países del Comité de Ayuda al Desarrollo de la OCDE. La cifra de $1998(0,26 \%)$ es todavía una previsión.

(38) En particular, tal y como plantea la COORDINADORA ESPAÑOLA DE ONGD: la referencia a la promoción de la economía española como un objetivo de la ayuda, aunque ésta haya sido matizada y situada en coherencia con el resto de objetivos y principios; el recorte de funciones del Consejo de Cooperación y el que no exista una garantía de interlocución adecuada con la administración; lainclusión del fomento del sector privadoentre las prioridades sectoriales, ya que no garantiza que se dirija a iniciativas como las cooperativas, microempresas y pequeñas empresas, que beneficiarían a los sectores de población más desfavorecidos; la confusa concepción de los créditos concesionales; la no inclusión de los países menos avanzados en las prioridades geográficas; la escasa selección de prioridades sectoriales; la inclusión como ayuda al desarrollo de las operaciones de mantenimiento de la paz y el olvido de la política europea de cooperación en la propia redacción de la ley.

La catástrofe del Huracán Mitch, ocurrida precisamente ya concluido este texto, ha puesto sin embargo de manifiesto la reacción solidaria de la sociedad española ante problemas de esta naturaleza. Pensamos que el gobierno va por detrás de la sociedad en esta materia. 
En resumen, no creemos equivocarnos mucho si afirmamos que la debilidad de estas políticas tan esenciales se explica por la prioridad dada a otros aspectos -más coyunturales - de la política económica nacional (39).

\section{En conclusión: ¿más de lo mismo?}

Hubiéramos deseado abordar algunas políticas sectoriales, tales como la política agraria y rural-tan inevitablemente «colgadas» de Bruselas-(40), la política de ayuda a las PYMES, la política presupuestaria propiamente dicha, la medioambiental o la hidrológica etc. Pero no podemos alargar más este ya extenso texto.

Al intentar enjuiciar la política económica del gobierno, como hemos hecho en este artículo editorial, hay que partir de la constatación de que según la mayoría de los observadores, dicha política se ha saldado hasta la fecha con unos resultados relativamente satisfactorios. En esa opinión coinciden desde el último informe de la OCDE ( España está logrando sus mejores resultados económicos desde finales de los años 80») (41) hasta comentaristas tan poco sospechosos como el ya citado profesor IGNACIO Sotelo ( Después de haber pasado con un notable alto la asignatura de economía y con una nota inferior, pero todavía aceptable, la de política social...») (42).

Dicho esto, y empezando con las opciones básicas, en el fondo de la política económica del gobierno actual, como condicionante estructural de todo, está el proyecto europeo. Nada en ello le diferencia del gobierno socialista: es el factor de continuidad más radical. En el fondo, como decíamos más arriba, es la propia sociedad española quien desde hace décadas ha optado-explícita e

(39) Quizás podamos hablar de «la soledad de la política de convergencia» del PP como en 1993 hablábamos de «la soledad de la política monetaria» refiriéndonos al gobierno socialista(Cf. Consejo de Redacción (1993), op. cit. p. 182).

(40) Sobre un caso paradigmático de esta política nos manifestamos extensamente en el reciente editorial sobre la reforma de la OCM del aceite de oliva: CONSEJODE REDACCIÓN(1998).«La batalla del aceite ...y otras batallas». Revista de Fomento Social, $\mathrm{n}^{\mathbf{0}} 209$, enero-marzo, pp. 3-29.

(41) OCDE (1998).--Estudios económicos de la OCDE 1997/1998. España. Ed. OCDE, Cf. p. 13.

(42) Ignacio Sotelo.- «La segudna transición», El País, 27 de octubre de 1998. 
implícitamente-por el modelo europeo, materializado en la compleja y cada vez más integrada construcción jurídica que llamamos Unión Europea. La cuestión que cabe plantear a este respecto, más allá de esa especie de «determinismo europeo» a que hemos hecho referencia, es la sensación que produce la política europea del PP de eludir el debate de fondo sobre el modelo de Europa al que aspira: en las opciones estratégicas de la construcción europea da la impresión de que la actual política exterior española carece de modelo propio.

Por otra parte, en la política económica del gobierno popular creemos detectar una absoluta preponderancia de los elementos coyunturales; realmente se ha desarrollado poca actividad de planificación económica a largo plazo, seguramente porque el peso de la coyuntura y de las restricciones exógenas es muy grande e imposible de soslayar. No es un fenómeno específico español; diríase que en la política económica de todos los países «manda la coyuntura». Calendarios tan precisos y urgentes como el examen de convergencia de mayo de 1998, la entrada en vigor del euro el 1 de enero de 1999, etc. parecen condicionar de manera inevitable la actividad del gobierno. Da la impresión de que no hay más proyecto nacional de verdadera entidad que la incorporación a Europa y que, en todo lo demás, se dan ciertos bandazos precisamente en función de la coyuntura. En cualquier caso, desde hace muchos años el peso de las restricciones exógenas en la política de los países europeos es una constante fácilmente detectable, sea cual fuere la situación política y el gobierno de turno.

Destaca entre esos elementos citados la preocupación efectiva y eficaz por mantener el rigor presupuestario. La necesidad de cumplir las estrictas condiciones del Pacto de Estabilidad, sobre todo en lo relativo al déficit público, están detrás de este rigor y un gobierno del PSOE en estas circunstancias no hubiera podido responsablemente permitirse muchas «alegrías» en materia de gasto público como sí sucedió en anteriores legislaturas socialistas, especialmente antes de la firma del Tratado de Maastricht. Es indudable que el gobierno popular ha dado, por así decirlo, «una vuelta de tuerca» en la disciplina presupuestaria.

Las diferencias se sitúan probablemente más en los matices, que son sin duda importantes. Probablemente la intensidad y los acentos puestos en determinados aspectos de la política económica sean los que diferencian al gobierno del PP del anterior gobierno del PSOE. En el fondo, se repite en España un fenómeno general en los países europeos de nuestro entorno: dadas las escasas diferencias 
de fondo en las políticas económicas de conservadores y socialdemócratas, es en los matices, en los acentos y las prioridades donde realmente se constatan dichas diferencias.

En cuanto al talante y los matices hay ciertas diferencias que ya hemos mencionado, en particular una mejor predisposición negociadora (por ejemplo con los sindicatos) (43), una indudable ambigüedad en el modelo perseguido, una oscilación entre las tendencias más neoliberales y las centristas, una cierta mayor claridad en las prioridades.

En relación a las prioridades, las acciones de política económica de este gobierno han venido determinadas, como se ha dicho, a veces, por razones ideológicas, pero, más frecuentemente, han sido el resultado de ciertos condicionamientos externos -nuestra participación en Europa-e internos -la necesidad de pactar con los gobiernos catalán y vasco para alcanzar la mayoría parlamentaria suficiente-.

Así, sin pretender agotar el tema, aparecen unas claras prioridades de esta política:

- El cumplimiento de las condiciones de convergencia y del pacto de estabilidad.

- La mejora de la competitividad de la economía española.

- La liberalización del mercado de trabajo y, en menor medida, de los mercados de productos y servicios.

- La defensa de los intereses españoles en la UE, ya que una vez alcanzada la UM, las autoridades comunitarias han comenzado a preocuparse del día a día de la economía europea.

- La reforma de la asignación del IRPF para incrementar la autonomía de las haciendas territoriales.

La mayor parte de estas prioridades fueron también decisiones en la política socialista, lo que confirma el diagnóstico de continuidad que vamos a formular. Ha sido el mayor énfasis en estas políticas, la decisión clara por todas ellas lo que puede diferenciar al gobierno del PP del PSOE; es decir, los matices a que también antes nos hemos referido.

(43) A títulode anécdota significativa, no deja de llamar la atención que el conflictode lafactoría de Ford en Valencia del verano pasado comenzara a resolverse tras la intervención mediadora del presidente popular de aquella Comunidad Autónoma, Sr.ZAPLANA. 
Hace ya más de cinco años, al concluir el artículo editorial del $n^{\circ} 190$ citado al comienzo sobre diez años de política económica del gobierno socialista, decíamos lo siguiente:

«Ladécada socialista deja sin duda a España abierta al entorno internacional desde el punto de vista económico, e indisolublemente inserta en Europa («...para bien y para mal»). Por eso algunos de los problemas no resueltos no son específicamente españoles, y no admiten una solución «española», aislada del contexto internacional.

Su tendón de Aquiles es sin duda la incapacidad del sistema económico para crear empleo y resolver el gravísimo problema del paro. En este caso se trata probablemente del agotamiento de un modelo de crecimiento que necesitaría cambios mucho más radicales, por ahora fuera de la mayoría de los programas económicos y políticos...» (44).

Al llegar al final del balance realizado en este artículo editorial, tras casi tres años de gobierno del PP, esas palabras siguen siendo de aplicación a la situación actual. Pero a la vez nos permiten remachar una idea que nos parece incuestionable: a la hora de hacer un balance global, creemos que en la política económica del PP predominan en el fondo los elementos de continuidad con la política económica del PSOE frente a los de ruptura, los de semejanza frente a los de diferencia. Bien es verdad, que el tiempo transcurrido desde el triunfo de los socialistas hasta la actualidad, ha permitido a los gobiernos -iy a la sociedad en su conjunto!-ir avanzando en un proceso continuo de clarificación de los objetivos pretendidos para nuestro país, y paralelamente, en una intensidad mayor o en una mayor decisión en la aplicación de las políticas. Esto supone, en el fondo, que los márgenes de opción son escasos y/o que existe un consenso social fundamental, más allá de las diferencias ideológicas y de programa entre los partidos. Si esto fuera verdad, la pregunta inquietante que nos hacemos, al menos en el terreno de la política económica es la siguiente: ¿invalida esta realidad la alternancia misma de los partidos?; ¿exige un replanteamiento a fondo de las funciones del gobierno y de la oposición?

Tras el triunfo electoral del SPD de Schröder en Alemania, el gobierno

(44) Consejo de Redacción (1993).- Op. cit. p. 187-188. 
conservador de José María Aznar «se ha quedado solo» en Europa. La ola socialdemócrata ha barrido el continente y ha impuesto su mayoría en casi todos los gobiernos de la Unión Europea, y desde luego, en los países más importantes. Cabe preguntarse, con razón, si la «excepción española» es flor de un día, o si los resultados de la política del actual gobierno le auguran un futuro electoral prolongado.

A ese propósito, quizás no esté de más volver sobre una reflexión, no por maquiavélica menos realista, acerca del ejercicio de la política. El objetivo fundamental de los políticos que tienen el poder es perpetuarse en el mismo, y el de los que no lo tienen o lo han perdido, es alcanzarlo o recuperarlo: se trata de un axioma básico. Y para conseguir el poder, en las sociedades democráticas avanzadas, es preciso ganarse el acatamiento y el apoyo político de la mayoría de los que votan. Pues bien, o mucho nos equivocamos, o al gobierno Aznar las urnas lo examinarán del empleo. Todas las encuestas de opinión colocan a esta variable, junto con el final del terrorismo, en lo más alto del ranking de las preocupaciones ciudadanas. Y es que, en una sociedad madura y culta, nos viene bien recordar que no somos súbditos, sino ciudadanos y que además de votar nos corresponde informarnos, opinar, y de esa forma hacer llegar a los políticos nuestros verdaderos deseos y objetivos. A ese fin confían haber contribuido las reflexiones de este artículo editorial.

«Puede decirse que son tres las cualidades decisivamente importantes para el político: pasión, sentido de la responsabilidad y mesura»: invitamos para terminar a cada uno de nuestros lectores - utilizando esas palabras de MAX WEBER (45)a preguntarse hasta qué punto el gobierno actual posee realmente esas cualidades (46).

(45) MAX WeBer [1919](1981).--El político yel científico. Ed. Alianza, Madrid, 7ª edición, p. 153.

(46) Los lectores que lo deseen pueden hacernos llegar sus comentarios y críticas a estas reflexiones, sea por sistema postal ordinario, sea porcorreo electrónico a:amorales@etea.com. 